\title{
Os difíceis caminhos percorridos pela Lei de Anistia no Brasil, do estudo de caso ao contexto nacional
}

\author{
Isabel Bilhão \\ Universidade de Passo Fundo \\ Passo Fundo, RS, Brasil \\ isabelbilhao@upf.br
}

Rodeghero, Carla Simone; dienstmann, Gabriel; trindade, Tatiana. Anistia ampla, geral $e$ irrestrita: história de uma luta inconclusa. Santa Cruz do Sul: Edunisc, 2011.

A obra aqui resenhada é fruto de uma empreitada coletiva, iniciada em 2007 e concluída em 2009, na qual se envolveram uma professora do Departamento e da Pós-Graduação em História da Universidade Federal do Rio Grande do Sul (UFRGS), Carla Simone Rodeghero, e os alunos Gabriel Dienstmann e Tatiana Trindade, ambos bolsistas, além de vários outros estudantes de história que atuaram como colaboradores voluntários.

Essa peculiaridade da feitura coletiva, não apenas da coleta de informaçóes empíricas, mas também da análise e interpretação das fontes e da escrita do livro, em meu entendimento merece destaque por se tratar de um raro e elogiável exemplo de conjugação das atividades de ensino e pesquisa, extrapolando as hierarquias acadêmicas tradicionais e permitindo a conjugação de esforços e inteligências de todos os atores envolvidos, evitando, no entanto, a armadilha da dispersão analítica, que em muito poderia prejudicar a compreensão da obra.

Em relação ao título, os autores explicam que sua escolha deveu-se à intenção de destacar, na primeira parte, o slogan que, nos anos de 1978 e 1979, marcou a campanha, esclarecendo que nem sempre se lutou por uma anistia nesses termos, e também que nem todos os envolvidos em sua defesa a entendiam dessa maneira. A obra, portanto, examina as diferentes visões de anistia que então conviveram e concorreram: de um lado, uma concepção mais radical (ampla, geral e irrestrita), que propunha o desmonte do estado de segurança nacional e, do outro, aquela que via a anistia como esquecimento. Em relação ao subtítulo, esclarecem que a caracterização dessa luta como "inconclusa" deveu-se à constatação de que seus objetivos não foram alcançados em 1979, fazendo com que uma parte dos militantes seguisse em campanha, enfatizando a necessidade de esclarecimento das mortes e desaparecimentos e a responsabilização dos agentes do Estado pelas violaçôes de direitos humanos, questôes ainda candentes nos dias que correm.

A pesquisa analisou, inicialmente, os documentos do acervo privado de Lícia Peres e Mila Cauduro, doados ao Acervo da Luta contra a Ditadura, com sede na cidade de Porto Alegre. Ambas dirigiram o Movimento Feminino pela Anistia (MFPA) e tiveram o cuidado de preservar os registros tanto dessa entidade quanto de outras com as quais ela se relacionava. Tal zelo, ainda pouco disseminado em nossas instituições e entidades, permitiu aos historiadores acessar correspondências, livros de atas, recortes da cobertura jornalística sobre a campanha e sobre a atuaçáo do MFPA, além de documentos sobre o núcleo gaúcho do Comitê Brasileiro pela Anistia (CBA), relatórios das reuniôes e encontros nacionais, cartazes, panfletos e fotos. O contato com esse material, que foi digitalizado e organizado cronologicamente pelos autores, possibilitou conhecer as açóes e as concepçôes do Movimento no Rio Grande do Sul, bem como seu relacionamento com núcleos de outros estados, especialmente São Paulo e Brasília.

Além dessas fontes, os pesquisadores também contaram com entrevistas concedidas por pessoas 
envolvidas na campanha pela anistia. Com base nesses relatos, puderam alargar suas visóes iniciais sobre o tema, confrontar e aprofundar as informações encontradas nos outros acervos e conhecer as percepçóes e vivências daqueles que se envolveram diretamente com o movimento. Entre eles estavam estudantes, ou militantes do Movimento Democrático Brasileiro (MDB), da CBA-RS, do MFPA. Entretanto, é preciso ressalvar que tais entrevistas aparecem na forma de excertos, pois, conforme os autores, o uso mais exaustivo desse material excederia os limites do trabalho atual. Aos leitores fica a promessa de que tais entrevistas serão oportunamente tratadas em um novo livro.

$\mathrm{Na}$ busca de indícios de como a campanha chegou à Assembleia Legislativa do Rio Grande do Sul, foram analisados os argumentos pró e contra a anistia, presentes nos discursos dos parlamentares. Além disso, a pesquisa revelou o importante apoio fornecido por deputados ou funcionários do MDB ligados ao movimento, especialmente no quesito infraestrutura: o uso de espaços para reuniōes, telefones e máquinas de escrever. Ainda no âmbito parlamentar, o livro destaca apoios de deputados federais e senadores, por meio de apresentação de emendas e de substitutivos ao projeto de anistia encaminhado pelo governo Figueiredo, que tramitou no Congresso Nacional, no período de junho a agosto de 1979.

Também serviram como fontes à investigação, charges e reportagens, publicados na imprensa alternativa, em veículos como o Coojornal, $O$ Rio Grande, Movimento, Em Tempo; panfletos e outros materiais guardados pelos entrevistados e fotos da campanha, encontradas tanto no Núcleo de Pesquisa em História da UFRGS, quanto em outros acervos.

O cruzamento das informaçóes, opinióes e impressóes obtidas a partir da análise de todas essas fontes permite à obra enfocar tanto o desenrolar do movimento no Rio Grande do Sul, quanto em outros locais do país. Para a elaboração das análises, os pesquisadores optaram por confrontar as fontes com perguntas que foram surgindo no desenrolar da investigação. Entre elas, se destacam as que refletem sobre o significado que a anistia foi ganhando ao longo do movimento, de meados da década de 1970 até 1979, permitindo ao leitor compreender como os usos políticos da anistia foram plurais e mudaram de acordo com o contexto e com as perspectivas e compromissos dos atores envolvidos.

A opção por uma metodologia que privilegiou a análise das contradiçóes e conflitos, apresentada com base na cronologia dos acontecimentos, acabou por marcar a própria organização do livro.

Assim, o primeiro capítulo, que compreende o período de 1975 a 1977, trata dos "primeiros tempos da luta", ou seja, da criaçáo do MFPA e de suas formas iniciais de ação, entre outras, a coleta de assinaturas, a divulgaçáo da causa e o contato com políticos e autoridades, além da busca do apoio da Igreja Católica, por meio de apelo ao pouco receptivo cardeal arcebispo de Porto Alegre, d. Vicente Scherer. Nesta parte do livro também são analisados o contexto e os limites da "política de distensão" do período Geisel e suas implicaçóes no desenrolar da campanha pela anistia, especialmente a aproximação entre o MFPA e o MDB, que, por meio de seus deputados, começava a manifestar apoio público ao movimento.

O segundo capítulo trata da "consolidação da luta", entendida como o momento de criação e ampliação dos Comitês Brasileiros pela Anistia, enfatizando a realização do I Congresso Nacional pela Anistia, em 1978. Nessa parte também são analisadas as reciprocidades entre as ditaduras do Cone Sul e a prisão de militantes brasileiros em cárceres uruguaios e argentinos, as quais ensejaram a realização das campanhas pela libertação de Flávia Schilling, presa em Montevidéu, e de Flávio Koutzii, em La Plata, na Argentina. Ambos os casos atingiram repercussão internacional.

Flávia Schilling foi solta e pôde retornar ao Brasil, em abril de 1980. Koutzii foi expulso da Argentina e retornou à França em junho de 1979, naquele país graduou-se em sociologia, apresentando, como trabalho de conclusão de curso, o relato de sua experiência nos cárceres argentinos. Quando retornou definitivamente ao Brasil, em 1984, esse trabalho foi publicado no livro Pedaços de morte no coração. 
O terceiro capítulo, intitulado "O enfrentamento (1979...)", analisa os limites do projeto da Lei de Anistia, apresentado pelo governo, bem como o desenrolar de sua tramitação e aprovação no Congresso Nacional. Entre as principais críticas da oposiçáo ao projeto estavam as limitaçóes no alcance da anistia e a defesa da reciprocidade, que, uma vez aprovada, indultaria tanto opositores quanto agentes do regime; tal proposta vinha sendo repudiada desde a realizaçáo do I Congresso Nacional pela Anistia. Os autores advertem que "parte dos que empunharam a bandeira da anistia ampla, geral e irrestrita, no entanto, silenciou a respeito da punição dos torturadores" (p. 191). Nessa parte do livro são analisadas ainda as manifestaçôes de entidades dos atingidos por atos institucionais, caso, entre outros, dos servidores da Petrobras e do Banco do Brasil e dos militares expurgados, bem como o contexto de efervescência sindical e grevista daqueles anos, fatores que, se entrelaçando à campanha pela anistia, desnudavam a precária situação do regime.

A última parte do livro, denominada "(In) conclusóes", trata das repercussóes e das modificaçóes pelas quais passou a Lei 6.683/79 nos anos posteriores à sua aprovaçáo, bem como da continuidade do movimento tanto em âmbito estadual quanto nacional, e apresenta ainda uma reflexão sobre os processos de anistia no Chile, Argentina e Uruguai, apontando os distintos caminhos políticos, jurídicos e administrativos percorridos por esses países, o que permite ao leitor a ampliação do conhecimento sobre as diferenças do processo de redemocratização brasileiro em relação ao contexto sul-americano.

Além de vasta bibliografia, ensejando o aprofundamento do assunto por parte de estudantes e demais interessados, a obra contém um índice onomástico, que permite a consulta dinâmica e imediata aos personagens de interesse do leitor e ainda, em anexo, a íntegra da Lei de Anistia, com as anotações das mudanças e subtraçôes realizadas no texto nos anos subsequentes, possibilitando a observação da continuidade e da contundência dos embates em torno da Lei após sua aprovação pelo Congresso Nacional.

Um dos grandes méritos da obra é pautar-se pelo rigor da pesquisa histórica, em uma análise que, partindo do âmbito local, entrecruza fontes de diversos acervos para, na contextualização mais ampla, permitir a compreensão dos limites, contradiçóes e significados da campanha pela anistia no Rio Grande do Sul em suas correlaçóes e implicaçôes com os demais estados brasileiros, fugindo assim das generalizaçóes explicativas e das fórmulas simplistas.

Tal cuidado, aliado a uma narrativa agradável e de fácil compreensão, torna a obra muito proveitosa tanto para o público acadêmico especializado quanto para todos aqueles que se interessam pela história e pelo aprofundamento da democracia e da cidadania em nosso país. 